\title{
Inventário da Comunicação
}

\author{
Urbano Nobre Nojosa'
}

I - PUC/SP

São Paulo (SP), Brasil

\author{
AGUIAR, L.; BARSOTTI, A. (Orgs.). \\ Clássicos da Comunicação: \\ os teóricos. De Peirce a Canclini. \\ $1^{\text {a }}$ ed. Rio de Janeiro: Vozes; \\ PUC-Rio, 2017, 400 p.
}

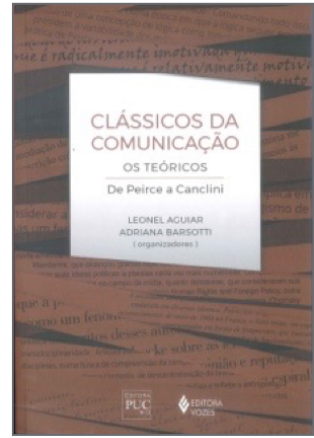

Resumo: A coletânea Clássicos da comunicação: os teóricos traz uma genealogia dos pensadores da área de comunicação social, demonstrando a diversidade de matrizes entre pensadores que contribuíram para formação inaugural de um campo epistemológico e sua influência na formação acadêmica brasileira.

Palavras-chave: comunicação; epistemologia.

Abstract: Communication inventory - The collection of essays Clássicos da comunicação: os teóricos (Classics of communication: the theoreticians) unfolds the genealogy of thinkers in the social communication field. It presents the diversity of inceptions among thinkers who contributed to the seminal formation of this epistemological field, as well as their influence on the Brazilian academic development.

Keywords: communication; epistemology.

Um caminho para analisarmos a coletânea de artigos Clássicos da Comunicação: Os teóricos, organizada por Leonel Aguiar e Adriana Barsotti, em publicação conjunta das editoras Vozes e PUC Rio, é aquele que aparece na declaração de Jorge Luis Borges (O livro) de que "Em todo Oriente ainda existe o conceito de que um livro não deve revelar as coisas; um livro deve, simplesmente, ajudar-nos a descobri-las" (BORGES, 2001, p.191). 
Um caminhar capaz de experimentar o mundo e ampliar o conhecimento vicário.

Essa seleção de textos e autores trata de inventariar, teórica e culturalmente, a produção de intelectuais que conformaram o campo da comunicação social, possibilitando aos leitores deslindarem percursos tradutórios para criar diálogos entre a tradição e o momento político e cultural que atravessa o País, momento vivido com ameaças ao processo democrático mascarado na agenda cotidiana das mídias.

Livros clássicos nos orientam na compreensão desse retorno de ideais conservadores e odiosos, manifestados pela política e reproduzidos pelos noticiários midiáticos, que demonstram as tensões históricas e conjunturais para pensarmos o que devemos ler. Um bom exemplo do que deveríamos ler do passado, para entender melhor nosso presente, aparece no sexto capítulo Paul Lazarsfeld (1901-1976), no artigo do professor da Pós-Graduação em Comunicação e Cultura Contemporânea da Universidade Federal da Bahia Giovandro Marcus Ferreira, que demonstra as influências da mídia na escolha do voto a partir da influência de grandes jornais nos processos decisórios dos eleitores. No comentário de Ferreira sobre o livro de Lazarsfeld, The People's Choice (A escolha do Povo) fica evidente que:

A escolha do voto articulado, com a influência dos meios de comunicação leva "a retenção de quatro termos-chave: contatos pessoais, grupo de pertença, reforço e líder de opinião." A conclusão que chega Lazarsfeld e seus colegas é um distanciamento ou negação da hipótese do isolamento dos indivíduos. Muito pelo contrário, eles (os indivíduos) estão enredados em inúmeros grupos, que tornam suas escolhas um ato complexo tecido nas e pelas relações sociais cotidianas. Os grupos são formados, por interesses comuns, tendo eles origens diversas: família, trabalho, escola, bairro, igreja, etc. (FERREIRA, 20017, p. 89)

A coletânea foi exposta a partir de um critério cronológico de organização e apresentação dos teóricos, considerando o primeiro com Charles Sanders Peirce (18391914), Ferdinand de Saussure (1857-19130), Walter Benjamin (1892-1940), Roman Jakobson (1896-1982), Paul Lazarsfeld (1901-1976), Harold Lasswell (1902-1978), Theodor Adorno (1903-1969), Wilbur Schramm (1907-1987), Marshall McLuhan (1911-1980), Roland Barthes (1915-1980), Elisabeth Noelle Neumann (1916-2010), Edgar Morin (1921), Noam Chomsky (1928-), Jürgen Harbemas (1939-), Guy Debord (1931-1994), Umberto Eco (1932-2016), Jesús Martín-Barbero (1937-) Eliseo Verón (1935- 2014), Maxwell E. McCombs (1938-) e o derradeiro Nestor Garcia Canclini (1939-). A seleção envolve a obra de 20 pensadores de diversas áreas de conhecimento que convergiram para a temática da comunicação social a partir das ciências sociais, lingüística, semiótica, antropologia e da própria área da comunicação social.

Outro critério dessa coletânea encontra-se na justificativa de que essa lista de autores consta como prática de leitura e debate nas bibliografias de estudos realizados nas 
pesquisas acadêmicas, pois entre as demandas da atualidade encontra-se a necessidade de fomentar o debate teórico com estudantes de pós-graduação nos correspondentes 46 cursos de mestrado, 24 cursos de doutorado e quatro mestrados profissionais vigentes no país nesse momento, de acordo com a Capes/MEC. Na graduação, na área de comunicação social há cerca de 221 mil alunos matriculados de acordo com Inep/MEC. Esse universo de estudantes poderá ter contato com esses pensadores no momento inaugural de suas respectivas formações, tanto no campo intelectual como no cultural.

Entre as orientações que faz Italo Calvino em Por que ler os clássicos, há aquela que sugere que tenhamos cuidados extras na seleção teórica atinente à formação intelectual e acadêmica desses milhares de futuros profissionais da comunicação social. Por isso um clássico: “... é um livro que vem antes de outros clássicos; mas quem leu antes os outros e depois lê aquele, reconhece logo o seu lugar na genealogia" (CALVINO, 1993. p. 14).

Ou quando defende Calvino que um clássico perpassa pela peleja entre os rumores e traços impregnados pela disputa do imaginário de questões ordinárias do cotidiano, com assuntos urgentes, que aparentemente são conflitantes com as demandas da atualidades. Para Calvino:

Os clássicos são aqueles livros que chegam até nós trazendo consigo as marcas das leituras que precederam a nossa e atrás de si os traços que deixaram na cultura ou nas culturas que atravessaram (ou mais simplesmente na linguagem ou nos costumes). (CALVINO, 1993, p.11)

Para essa primeira leitura da coletânea Clássicos da Comunicação: teóricos, devemos pensar sobre o papel da construção epistêmica, como ferramenta capaz de problematizar questões históricas e conjunturais a partir de uma reflexão teórica, que, a priori, trata de fazer perguntas, pesquisar, investigar, forjar reflexão, contemplação e introspecção, como também formular raciocínios, capazes de compreender fenômenos cotidianos, sociais e especulativos dos processos comunicacionais. Por isso, essa coletânea de artigos foi realizada por especialistas, doutores convidados para tratar sobre cada autor, como reconhecimento da diversidade dos grupos de pesquisas e suas instituições de ensino abrangendo o território nacional, como percebemos pela lista de autores: Lucia Santaella (PUC/SP), Denise Lima (UFPB), Vanessa Salles (FUMEC), Silnei Soares (UNICENTRO), Giovandro Pereira (UFBA), Rafiza Carvalho (UCB), Yuji Gushiken (UFMT), Heloisa Moraes (UNISUL), Frederico Tavares (UFOP), Danila Lage (UFMG), Iluska Coutunho (UFJF), Célia Mota (UNB), Adilson Filho (UFF) Eula Cabral(IBICIT), Anita Leandro (UFRJ), Isabel Castro (ECO/UFRJ), Gabriela Almeida (ULBRA), Marcos Silva (UFMS), Maria Gobbi (UNESP), Jan Prado (UFOP), Maria Coelho (UFRN), Sebastião Filho (UFRN).

Este é um livro indispensável, cujo sentido efetivo que ele merece só os leitores podem Ihe dar. Por exemplo, percebendo os clássicos que não habitam suas páginas e foram olvidados; buscando os paradoxos e debates entre os autores escolhidos; transitando por suas páginas de maneira rizomática, talvez para seguir a lição deleuziana de que 
o livro está no fora e no para fora.

Um livro, por outro lado, desde sua longa tessitura histórica, como objeto possível de realização da leitura do mundo, pode ser organizado de muitas maneiras. Aqui temos uma que já nasce nomeando quem são os clássicos de um dado campo do conhecimento, em torno de uma linha temporal linear, como se autores e idéias progredissem positivamente, ao invés de oferecer, aos jovens e maduros leitores, caminhar pelas sendas de controvertidas polêmicas e Ihes ajudar, desde cedo, a fazer escolhas. Os clássicos, ademais, devem ser cozinhados em fogo baixo, para saber se sobrevivem ao calor da crítica depois de atravessar o ponto de fervura.

Urbano Nobre Nojosa é professor de jornalismo na PUC-SP e doutorando em Comunicação na PUC-SP.

unobre@gmail.com

\section{Referências:}

AGUIAR, L. ;BARSOTTI A. (Org) Clássicos da comunicação: os teóricos, Rio de Janeiro: Editora PUC/ RIO e Editora Vozes, 2017.

BORGES, J. L. Obras completas. V. 4, São Paulo: Globo, 2001.

CALVINO, I. Por que ler os clássicos. São Paulo: Companhia das letras, 1993.

DELEUZE, G.; GUATTARI, F. Mil platôs. Capitalismo e esquizofrenia, vol. 1, Rio de Janeiro: Editora 34, 1995. 